\title{
MARXISMO E ALIENAÇÃO ESTATAL: UM ESTUDO DE CASO SOBRE A PRODUÇÃO PARLAMENTAR NO CASO DO ROMPIMENTO DA BARRAGEM DE MARIANA
}

RESUMO: A partir da literatura marxista sobre Alienação Estatal, esse texto analisa a produção legislativa dos deputados estaduais do Espírito Santo no caso do rompimento da barragem de Mariana, em 2015. Ao observar a baixa propulsão de políticas públicas que contemplem as necessidades das vítimas e, em paralelo, o alto volume de proposições que visavam beneficiar a empresa causadora do rompimento, partimos da hipótese que as doações eleitorais interferiram no comportamento parlamentar. Para responder tal hipótese, traçamos uma construção teórica e empírica que analisa as doações e as ações dos beneficiados pela empresa.

Palavras-chave: Desastres socioambientais; Doações eleitorais, Alienação estatal

\section{MARXISM AND STATE ALIENATION: A CASE STUDY ON}

\section{PARLIAMENTARY PRODUCTION IN THE CASE OF THE BREAK OF MARIANA DAM}

ABSTRACT: From the Marxist literature on State Alienation, this text analyzes the legislative production of state deputies of Espírito Santo in the case of the Mariana dam rupture in 2015. Noting the low propulsion of public policies that address the needs of victims and In parallel, the high volume of propositions that aimed to benefit the company that caused the disruption, we assume that electoral donations interfered with parliamentary behavior. To answer this hypothesis, we draw a theoretical and empirical construction that analyzes the donations and actions of the beneficiaries of the company.

Keywords: Social and environmental disasters; Electoral donations; State alienation

\section{INTRODUÇÃO}

Uma pergunta tem movido diversos pesquisadores das Ciências Sociais, sobretudo da Ciência e Filosofia Política, há vários séculos: A quem serve o Estado? Acalorados debates traçam formas de pensamentos e ocuparam centenas de milhares de folhas de papel, nos quatro cantos do mundo. Grosso modo, se indaga se o aparato

\footnotetext{
1 Mestrando em Ciências Sociais. Universidade do Vale do Rio dos Sinos - Unisinos. E-mail: igor.amaral@live.com

Programas de Pós-Graduação em Ciências Sociais e Filosofia - UNIOESTE - Rua da Faculdade 645. Toledo - PR. CEP 85.903-000 Email: revistaalamedas@gmail.com
} 
estatal estaria, nas sociedades contemporâneas, a serviços dos cidadãos ou dos interesses do Capital? Maniqueísmos à parte, a respostas à essa indagação seria infinita.

Este trabalho não busca discutir essa questão, mas partir de uma lógica histórica e de grande repercussão no mundo ocidental: a marxista. Nesse campo ideológico, o conjunto de entes do Estado estaria à disposição do Capital. Seria ele uma ferramenta da burguesia para defesa de seus heterogêneos interesses. Em detrimento da sociedade, o cerne do Estado cooptado pelos detentores do Capital, aparelhado, e sujeito às pressões da classe abastada.

A partir dessa premissa, esse texto busca aproximar teoria e prática. Partimos de uma revisão bibliográfica sobre os escritos de Marx e Engels acerca das formas a alienação estatal. No texto, os autores denotam a aproximação do Estado com a civilburguesa para cooptação do aparelhamento estatal. Por questões de limite espacial, a revisão acerca dos autores tens fins de contextualização para engendrar uma construção que mistura preceitos teóricos e empiria. Ao revisitar a teoria marxista buscamos, nesse texto, emoldurar um recorte teórico para analisar um caso específico: as respostas do Poder Legislativo do Espírito Santo aos prejuízos causados pelo rompimento da barragem de Fundão, em Minas Gerais em 2015. Nossa hipótese é que as doações eleitorais feitas pela Vale, controladora da barragem, tiveram significativa relevância no comportamento dos parlamentares.

Esse texto faz parte uma série de pesquisas desenvolvidas pela rede Com Rio, Com Mar, financiada pela Capes e Agência Nacional de Águas, que tem como objetivo entender e analisar as instituições e políticas públicas implementadas após o crime ambiental de Mariana. A contribuição desse texto, nesse sentido, procurar responder os motivos da baixa produção legislativa, no estado do Espírito Santo, descoberta realizada em outra pesquisa feita pela rede Com Rio, com Mar. Partimos da lógica de cooptação do Estado, no nosso caso os deputados estaduais, pela empresa operadora da barragem, através da doação eleitoral.

Para responder a nossa questão, partimos de Marx e Engels, como já fora dito. Também agregamos os estudos sobre financiamento eleitoral e as ferramentas de cooptação do Estado por parte das mineradoras, nosso foco de interesse sobre o rompimento da barragem, e desembocamos num estudo de caso. Ao analisar quais deputados foram financiados pela empresa, descobrimos que sua atuação no caso do 
rompimento não fora para punir e buscar a mitigação dos prejuízos às vítimas, pelo contrário, em maioria, os parlamentares atuaram para beneficia a empresa. Embora um entrelaçamento complexo de teorias e empirias sejam necessárias para entender esse recorte do caso, a ciência é desafiante. E nesse desafio de fazer ciência, com dados, fatos e bibliografia, esse texto se lança.

\section{MARX E A ALIENAÇÃO ESTATAL}

A contraposição que circundam a sociedade civil-burguesa tem como elemento motor os conflitos entre classes sociais. Desta forma, a revolução que a traz à sociedade civil-burguesa tem uma "nova ordem", quando as contradições dessa ordem se explicitam tornando as relações sociais burguesas anacrônicas se transformam. Segundo Marx, esse mecanismo enseja, sobretudo, depois da violenta repressão ocorridas em Junho de 1848, período de desacreditação dos elementos progressistas burgueses. Neste período, o proletariado vindo do campo liberta-se da repressão feudal e cai nas mãos do capital, o proletariado urbano encontram-se em condições sub-humanas. Assim, a relação entre Burguesia e Povo torna sem efeito, os burgueses não são mais uma classe democrática.

Segundo Marx (1998, p.13), o Estado Moderno "não passa de um comitê para gerenciar os assuntos comuns de toda a burguesia", esta, então, seria a nova ordem, com uma forma de alienação dos mecanismos do Estado. O "governo da sociedade" desmembrado das forças sociais que a dão estrutura, ao mesmo passo, em que a divisão do trabalho orientada pelo capital tem seu ápice no Estado. Ao caracterizar o Estado como um "comitê", Marx desnuda uma leitura essencial, segundo Pasukaim (1989): o estado não é somente uma forma ideológica, mas também, e simultaneamente, uma forma de ser social. A natureza ideológica do conceito não suprime a realidade e materialidade das relações das quais ele é expressão" (Pasukanis, 1989, p. 44). Nessa concepção, o comitê, tal qual caracterizado por Marx, tem materialidade e estrutura burocrática. É no meio dele que se os interesses das classes burgueses impõem seus interesses. Resssalta, ainda, Pasukaim, que não se pode tratar de "assuntos comuns de toda a burguesia", já que é uma classe social homogênea com interesses difusos, equacionados no Estado. 
Nessa Nova Era, o cidadão, em seu conceito abstrato, é ilusório. "A democracia formal do liberalismo privatiza o homem. O desaparecimento do cidadão não apenas corresponde ao empobrecimento e a uma desmoralização da vida pública (...), mas ao mesmo tempo significa uma mutilação do homem como indivíduo e como personalidade" (Lukács, 2007, p. 30). Logo, se a sociedade burguesa se estrutura dessa forma, aqueles que se estruturam numa dimensão universal não serão os "burgueses", mas o proletariado moderno, já que as tensões ocorridas na sociedade civil-burguesa têm única saída racional: a vitória do trabalho e a supressão do domínio do capital.

A sociedade analisada por Marx é, essencialmente, universal. No entanto, tal universalidade é, de fato, aquela das relações burguesas que têm alcance mundial. $\mathrm{O}$ universo da sociedade capitalista é, assim, inerente a vitória do particularismo burguês. Após a burguesia deixar de ter uma função revolucionária, o universalismo burguês passa a ser "principalmente depois que a burguesia deixa de ter um papel revolucionário, o universalismo burguês não passa de "frase" (embora tenha uma base real, a sociabilidade civil-burguesa, a configuração objetiva do gênero humano em-si (Cf. Lukács, 1966): se antes o racionalismo e o Iluminismo foram proeminentes, agora, o caráter irracional da ordem burguesa é patente.

O rompante da revolução política foi a mutação da realidade, sendo o estado fundamental nesse processo. Porém com a concretização da ordem do capital, o estado foi convocado, não para conduzir novas relações com altos custos, mas trazer um aparato a serviço da manutenção do velho.

O universalismo de antes e a eminência da noção de cidadania são postos em segundo plano e o gerenciamento toma a dianteira, dando novo aspecto a alienação estatal. A máquina estatal evolui e as autoridades (juristas, burocratas, militares...) fazem do estado um mecanismo em que o controle consciente é impossível. Isto é, o estado, que trouxe avanços consideráveis no princípio da sociedade civil-burguesa, quando esta se consolida e manifesta suas objeções mais indispensáveis, é algo que é efetivo na medida mesma de sua irracionalidade.

O regime é como disse Lívia Cotrim (2010, p. 25), "coágulo de forças sociais, genéricas, usurpadas de seus produtores e concentradas”, contudo, em sua evolução, relacionado àquele da ordem do capital, ele se coloca como uma potência estranha que escapa ao controle consciente. 
A citação, expressa no discurso cidadão, fora verdadeira quando declarava contraditoriamente seu oposto. Agora, a "citação" se vai e resta a individualidade da sociedade civil-burguesa, individualidade essa transferida para a classe estatal. Não é mais a população e a razão (com todas as ilusões que isso traz consigo) que estão no estado, mas "funcionário", aquele que somente se individualiza na sociedade civilburguesa por ser uma mera personificação de uma relação alienada, uma "função" socialmente necessária à ordem existente. O regime estatal que, com a "razão do estado", acreditara dominar as condições em que se punha, torna-se uma comissão colocada à disposição da ordem burguesa.

Para que essas evidências fiquem mais claras, primeiramente, vejamos como Marx enxerga o estado sob Napoleão para depois se analisar como ele o enxerga com Luís Napoleão:

\begin{abstract}
A primeira revolução francesa, com sua tarefa de quebrar todos os poderes locais, territoriais, municipais e provinciais, para criar a unidade burguesa da nação, tinha que desenvolver aquilo que a monarquia absoluta havia iniciado: a centralização, mas ao mesmo tempo a extensão, os atributos, e os servidores do governo. Napoleão aperfeiçoou a máquina do estado. (...) Cada interesse comum destacava-se imediatamente da sociedade, contrapunha-se a essa como interesse superior, subtraía-se à atividade dos próprios membros da sociedade e convertia-se na atividade do governo, desde a ponte, a escola e os bens comunais de um município rural até as ferrovias, a riqueza nacional e as universidades da França (MARX, 2009 b, p. 323).
\end{abstract}

Marx enxerga o estado sempre ligado à sociedade civil-burguesa e a seus objetivos. Nisso, ele ressalta um movimento no qual ao mesmo tempo em que o "instrumento" do estado se aperfeiçoa, ele torna-se insólito aos membros da sociedade. Isso, na ordem burguesa que se estabelecia, fora um crescimento na medida em que a "unidade burguesa da nação" obtivera substancialidade com os "ganhos civilizatórios" da "nova ordem".

No entanto, evoluíram "a extensão, os atributos, e os servidores do governo" os quais pareceram se colocar acima da sociedade civil-burguesa na medida mesma em que ajudaram a implementá-la, sendo indissociáveis dessa. Nisso, se, como disseram Marx e Engels, "a divisão do trabalho só se torna efetivamente divisão do trabalho a partir do momento em que se opera uma divisão entre o trabalho material e o trabalho 
intelectual" (Marx; Engels, 2002, p. 26) a função estatal, logo, seria o pico máximo dessa divisão.

Isso não só por ele avançar com a sociedade civil-burguesa, em cujo contexto tal secessão se constitui de forma crescentemente irracional, mas também pelo óbvio: são pessoas que integram o estado, o "instrumento" estatal. Tal qual o capital, ele não uma coisa, mas um conjunto de relações sociais. Dessa forma, para que a ação do governo aparenta ser independente, frente à sociedade civil-burguesa, a mediação da organização hierárquica do estado deve se apresentar com importância crescente. $\mathrm{O}$ instrumento do estado não fora criado pela sociedade burguesa e seus representantes; antes, teve seu desenvolvimento sob a estabilização do estado nacional absolutista. No entanto, estes representantes, como Napoleão, aperfeiçoaram-na: passa-se do "variado mostruário de plenos poderes medievais dirigentes" ao "plano regulado de um estado cujo trabalho está dividido e centralizado como uma fábrica.” (Marx, 2009 b, p. 322).

Os conceitos de alienação e a reificação existente na composição da sociedade civil-burguesa, são também flagrantes no âmbito estatal. Os mecanismos como se externam o Estado, é de justa contraposição já que ele não é tampouco pode ser autônomo em relação à sociedade civil-burguesa. Ele aparece como uma força alheia cuja ação se daria de acordo com o "interesse comum" na medida em que a abstração (arregimentada na relação-capital e na circulação de mercadorias) que marca a "anatomia da sociedade civil-burguesa" é efetiva de modo marcante.

Nessa situação, a divisão do trabalho apresenta no Estado com força na proporção em que o interesse social aparece como se fosse um comando estatal auto racional, quando se aceitam as deduções reprodutivas do capital e se reproduz sua estrutura hierárquica na esfera estatal. Concluímos observando que em Marx e Engels contemplam que relações sociais alienadas cuja divisão do trabalho se estrutura com o controle alheio àquele que efetivamente produz.

\section{FINANCIAMENTO ELEITORAL BRASILEIRO E A RELAÇÃO SETOR DE MINERAÇÃO}

As relações entre o Estado e o Mercado são importantes pontos de tensão nas discussões aprofundadas sobre as democracias modernas. Ao observar as formas de 
cooptação dos interesses privados no seio do Estado, é fundamental contextualizarmos o financiamento privado de campanhas eleitorais. Ao estabelecer uma relação da econômica - e porque não de dependência- com empresas, o político passa defender os interesses dessas em detrimento do "bem comum"? Se partirmos dessa lógica, é fácil dizer que o Estado, então, estaria propenso a dar respostas satisfatórios aos pleitos daqueles grupos de interesse que se organizam de maneira mais estruturada para "atalhar" o processo de acesso às políticas públicas, através do capital.

Charles Lindblom (1977) entende que as empresas financiadoras ostentam uma posição privilegiada no processo de decisão política. A questão central que Lindblom (1977) investiga é até que ponto os Estados Modernos, amplamente ligados ao Mercado, seriam, de fato, democráticos. Para solucionar a complexa equação entre a soberania popular e representação de interesses, o autor discorre sobre o papel político do empresário. Lindblom (1977) chega, entre outras, a conclusão que os grupos de interesse, organizados pelo financiamento empresarial de campanhas, tomam das mãos do governo as decisões sobre políticas públicas. Lindblom (1977) não nega a coexistência de outros grupos privilegiados, mas ressalta que os grupos privados têm mais opções para influenciar, mesmo que de maneira informal, sua autoridade nos governos. Nos processos de identificação dos problemas, formação de agenda, formulação de alternativas e tomada de decisão, os financiadores têm posição singular na comparação aos "cidadãos comuns".

Para Lindblom (1977) é nítida a tensão entre as demandas oriundas do poder econômico a da sociedade civil. Para ele, geralmente os interesses políticos do capital estão sempre em choque com as dos cidadãos. Assim, as tomadas de decisão no espectro público são moldadas tal qual respostas às demandas privadas e, então, proclamadas como reformas democráticas. Através dos grupos de interesse, financiamento e partidos políticos, as demandas do capital têm larga vantagem na competição democrática, já que são importantes e singulares fontes de fundos, são organizadas (na comparação com o cidadão comum) e detêm acessos especiais aos membros de alto escalão do governo e do parlamento.

Ao fazer uma avaliação crítica dos estudos sobre a influência do capital na tomada de decisão do Estado, Smith (1995, p. 94) observa que, de fato, ela existe, no entanto, ela não abrange todos os níveis das políticas públicas. Para o autor, a influência 
do capital nas políticas ocorrem quando, pelo menos uma, das seguintes questões estão presentes: (a) quando se trata de assuntos de baixa capacidade midiática, (b) em pautas técnicas e especializadas, (c) quando os produtos de determinadas políticas são concentrados e os custos distribuídos entre os eleitores, (d) se o assunto não estiver inserido em espectros partidários e ideológicos, (e) quando a sociedade civil ignorar o tema da política em questão e (f) se o tema da política a ser discutido não fira outros interesses de grupos de financiamentos diferentes.

No Brasil, segundo Diniz e Boschi (2004), as formas de atuação destes grupos passaram por modificações nas últimas três décadas. A mais significativa para nosso estudo diz respeito ao aperfeiçoamento dos mecanismos de pressão através do financiamento eleitoral na participação no parlamento. Para os autores, houve um deslocamento das atividades orquestradas pelos interesses privados do Executivo para o Legislativo. Nessa mudança de alvo, o Poder Legislativo ganhou status de espaço de interlocução e expansão dos interesses e influência dos poderes de grupos empresariais.

Publicado em 2003, o estudo de David Samuels mostrou que, no Brasil, as doações de campanha seguem singularidades. Em geral, candidatos recebem doações de poucas empresas, as quais repassam altos montantes de dinheiros. Desta forma, surge um "oligopólio do financiamento", o acarreta num processo onde a desigualdade social se infla, já que os mais pobres passam a ter menos influência no processo político (SAMUELS, 2003, p.60).

A discussão fica ainda mais crítica se levarmos em consideração a observação feita por Nicolau (2002) de que é mínima a população que se interessa pela atuação de seu deputado e não o acompanha em sua tomada de posições. Autor observa ainda que parte da população sequer lembra em quem votou. Se tal acompanhamento, aqui também pode ser entendido como forma de accountability, não é feito pela população, quem é que o faz? Seus pares e os financiadores.

\section{PRÁXIS: O CRIME SOCIOAMBIENTAL DA SAMARCO}

No dia 5 de novembro de 2015, por volta das 16 h20, a barragem, na unidade de Germano, na cidade de Mariana, em Minas Gerais, entrou em colapso e rompeu-se. Operado pela empresa Samarco, o tanque de resíduos de mineração expeliu mais de 80 
milhões de toneladas de lama na Bacia do Rio Doce. Caso fosse dividido, cada brasileiro receberia aproximadamente 450 quilos de rejeitos da mineração. Ocorre que essa carga de dejetos foi toda depositada numa limitada área dos estados de Minas Gerais e Espírito Santo. Dezenove pessoas, entre membros das comunidades atingidas e empregados da Samarco e de empresas contratadas, morreram e pelo menos 500 mil pessoas foram afetadas direta ou indiretamente.

A realidade das pessoas atingidas, na emergência do desastre socioambiental e nos períodos sequentes, esteve estruturada no conjunto de relações socais totalmente desfeitas e esgarçadas. Embora a Samarco seja responsável por reparar os danos causados, como determinou o Termo de Transação e Ajuste de Conduta (TTAC) assinado entre Ministério Público, União e as empresas administradoras da barragem, o Poder Público permanece sendo o principal indutor e garantidor das ações de mitigação dos prejuízos acarretados à população atingida.

O Estado dispõe basicamente sobre dois tipos de competência para o repertório de ação na implementação de políticas públicas em desastres socioambientais: a competência Administrativa e a competência Legislativa. A primeira cabe ao Poder Executivo e diz respeito à faculdade para atuar com base no poder preventivo, repressivo ou simplesmente ordenador, ao passo que a segunda cabe ao Poder Legislativo e diz respeito à faculdade para legislar a respeito dos temas de interesse da coletividade. No entanto, a produção de repostas do Poder Legislativo aos prejuízos sociais do desastre no estado do Espírito Santo foi irrelevante, conforme pesquisa realizada. Para entender os motivos, partimos da hipótese que a influência financeira aplicada pela empresa através de doações de campanha - a Vale historicamente despencou altos montantes aos partidos políticos - impediu que a empresa fosse culpabiliza no caso. Para isso, nos trechos a seguir, faremos uma construção acerca das doações da empresa.

\section{A SAMARCO E AS DOAÇÕES DE CAMPANHA EM 2014}

O setor de extração mineral possui uma relação estrutural com o Estado brasileiro. A indústria de mineração possui relação estrutural com o Estado Brasileiro (Zonta e Trocate, 2016, p. 185). Desde os anos 1930, a União tinha como uma das suas 
principais preocupações o desenvolvimento do setor mineral e o elegeu como prioridade de suas ações. Com a exportação de matérias primas oriundas da exploração mineral, a economia nacional se garantia de entrada de moeda estrangeira no país e, consequente, conseguia realizar a importação de bens de capital para promover a incipiente industrialização do país (ZORZAL E SILVA, 2004; TRINER, 2011).

Zonta e Trocate (2016) observam que o crescimento do setor mineral foi em parceira com o estado, sobretudo com o poder Executivo Federal. Prova disso é que as principais companhias minerados do país, Vale (Companhia do Rio Doce) e a Companhia Siderúrgica Nacional (CSN) foram empresas estatais. Ambas acabaram sendo privatizadas ao longo dos anos 1990. Uma das provas que o setor mineral passou a ser prioridade para o governo Federal pode ser encontrada no Decreto-lei 3.365/1941 que dá o status de atividade de interesse público à mineração. Outro trecho de legislação nacional, no Código Mineral (DECRETO-LEI n 227/1967), estabelece que "qualquer medida judicial não poderá haver embargo ou sequestro que resulte em interrupção dos trabalhos de lavra”.

Conforme Zonta e Trocate (2016), as empresas mineradoras desenvolveram diferentes estratégias para influenciar os governos em prol de seus interesses. Alguns destes modus operandi não se aplicam somente em terras brasileiras, mas são identificadas em diversos outros países que essas empresas atuam. Entre as formas de cooptação do Estado para a defesa de seus interesses vão desde o lobby, assessoria direta, atuação de escritórios de advocacia e até mesmo casos de corrupção (Zonta e Trocate, 2016, p. 190).

Nas eleições para deputado estadual no Espírito Santo, escopo de interesse deste trabalho, o grupo Vale, administrador da Samarco, empresa que operava a barragem de Fundão e responsável legal pelo crime socioambiental, se utilizou de seis empresas para realizar doações aos candidatos, a saber: Vale Energia, Vale Manganês, Vale Mina do Azul, Minerações Brasileiras Reunidas, Mineração Corumbaense Reunida e Salobo Metais. Em âmbito nacional, essas empresas aplicaram R \$ 79,3 milhões em campanhas políticas. Especificamente, na disputa às vagas para Assembleia Legislativa do ES foram investidos $\mathrm{R} \$ 670.800,00 \mathrm{em} \mathrm{12,} \mathrm{dos} \mathrm{30,} \mathrm{deputados} \mathrm{eleitos.}$ 


\section{INTERESSES DO CAPITAL? AS REPOSTAS DO LEGISLATIVO AO DESASTRE}

Para descrever como a Vale penetrou no Estado, através da doação de campanhas, cruzamos os dados disponíveis no Tribunal Regional Eleitoral do Espírito Santo, onde constavam as doações recebidas por cada parlamentar, com as do resultado das eleições, disponíveis do site do Tribunal Superior Eleitoral, e a produção Legislativa, disponível no site da Assembleia Legislativa. Munidos dos dados, criamos duas tabelas, inseridas a seguir no texto. A primeira, mapeou quanto cada candidato recebeu do Grupo Vale e o percentual que estes montantes representaram nos valores totais arrecadados por cada candidato. Além disso, também destacamos os partidos de cada parlamentar e se estes estavam na coligação vencedora de eleição.

Já a segunda tabela, avaliou a posição de cada deputado com relação as pautas envolvendo o rompimento da barragem. Dos 12 financiados pela Vale, 10 propuseram medidas favoráveis à empresa. Outros dois, Sandro Locutor e Rodrigo Coelho, nada propuseram. Desta forma, classificamos, após análise do banco de dados da produção legislativa na Assembleia do Espírito Santo no que diz respeito ao caso da Samarco entre dezembro de 2015 e agosto de 2018, os parlamentares como Pró-Vale, aqueles que amplamente defenderam a empresa, e Inativos. Sendo os primeiros aqueles que moveram ações em benefício da empresa e o segundo grupo aqueles que não se manifestaram. A escolha da palavra inativo deriva da necessidade de conceituar a atuação dos deputados deste eixo. Sem aparecer nos relatórios da Assembleia como provedores de ações sobre a pauta do rompimento, eles não se manifestaram nem favoráveis ou contrários, tampouco estiveram neutros, já que neutralidade implica em um posicionamento, ação não praticadas por eles. Na segunda tabela ainda o leitor pode encontrar a posição dos parlamentares diante o Executivo sendo eles de oposição ou governistas.

Ao observar a lista dos parlamentares beneficiados, constatamos que não houve distinção partidária ou ideológica para o recebimento das doações. Os partidos MDB e PT foram os maiores beneficiados, tendo somado mais da metade das doações do grupo Samarco. No estado do Espírito Santo, a empresa seguiu a mesma premissa aplicada no âmbito nacional. Ao analisar os quase R $\$ 80$ milhões doados pela Samarco em todo o 
Brasil em 2014, a metade destes, $\mathrm{R} \$ 43$ milhões, foram para os dois partidos (Zonta e Troncate, 2016, p.191). Isso, entre outras alternativas, se dá ao fato que ambos os partidos concorriam à reeleição. No caso do Espírito Santo, o MDB era o favorito na disputa, através do governador eleito Paulo Hartung.

Tabela 1

\begin{tabular}{|c|c|c|c|c|c|}
\hline Candidato & Partido & $\begin{array}{l}\text { Coligação } \\
\text { governista }\end{array}$ & $\begin{array}{l}\text { Doação da } \\
\text { Vale }\end{array}$ & Doações Totais & $\begin{array}{l}\text { Percentual } \\
\text { Vale }\end{array}$ \\
\hline Hércules Silveira & MDB & Sim & $150.000,00$ & $348.406,97$ & $43,1 \%$ \\
\hline Guerino Zanon & MDB & Sim & $98.000,00$ & $488.016,70$ & $20,1 \%$ \\
\hline Luzia Toledo & MDB & Sim & $89.500,00$ & $329.767,89$ & $27,1 \%$ \\
\hline Janete de Sá & PMN & Não & $70.000,00$ & $203.136,54$ & $34,5 \%$ \\
\hline Marcelo Santos & MDB & Sim & $60.000,00$ & $720.133,91$ & $8,3 \%$ \\
\hline Bruno Lamas & PSB & Não & $45.000,00$ & $326.828,20$ & $13,8 \%$ \\
\hline Nunes & $\mathrm{PT}$ & Não & $44.000,00$ & $389.155,75$ & $11,3 \%$ \\
\hline Hudson Leal & PRP & Sim & $39.500,00$ & $196.437,36$ & $20,1 \%$ \\
\hline Gildevan & & & & & \\
\hline Fernandes & PV & Não & $30.000,00$ & $204.460,68$ & $14,7 \%$ \\
\hline Sandro Locutor & PPS & Não & $30.000,00$ & $250.150,00$ & $12,0 \%$ \\
\hline Padre Honório & $\mathrm{PT}$ & Não & $12.700,00$ & $105.350,09$ & $12,1 \%$ \\
\hline Rodrigo Coelho & $\mathrm{PT}$ & Não & $2.100,00$ & $337.123,94$ & 0,6 \\
\hline
\end{tabular}

Fonte: Elaboração própria com dados do Tribunal Superior Eleitoral.

Candidatos à Assembléia Legislativa do Espírito Santo ligados à chapa do governo foram aqueles que receberam os maiores montantes. $\mathrm{Na}$ lista dos 12 beneficiados, apenas um, o deputado oposicionista Brunos Lamas do PSB, aparece como recebedor de doações da empresa. Todos os demais compunham a base governista. Isso mostra que a empresa tem um foco: financiar aqueles ligados ao governo. Com isso, a aproximação com o Poder Executivo, que já é construída também pelas doações aos candidatos ao governo, fica mais estreita. Além de também ter, seus 
deputados privilegiados, maiores acessos às estruturas do governo local, facilitando a defesa dos interesses da empresa nos mais diversos setores do Estado.

A distribuição de montantes varia conforme os candidatos. Hércules da Silveira, do MDB, teve quase a metade dos recursos vindos do Grupo Vale. Sendo ele o maior beneficiário dos parlamentares capixabas da empresa. Em média, a empresa doou R\$ 55.900,00 para cada candidato, enquanto a média das doações totais foi de $\mathrm{R} \$ 324.914,00$. Embora os valores repassados pela empresa, analisando o grupo de deputados, represente baixo percentual na comparação com as doações totais, chama a atenção o comportamento dos parlamentares, depois de eleitos, na defesa dos interesses da empresa na Assembleia.

Tabela 2

\begin{tabular}{|c|c|c|l|}
\hline Candidato & Comportamento & Partido & Bancada \\
\hline Hércules Silveira & Pró-Vale & MDB & Governo \\
\hline Guerino Zanon & Pró-Vale & MDB & Governo \\
\hline Luzia Toledo & Pró-Vale & MDB & Governo \\
\hline Janete de Sá & Pró-Vale & PMN & Governo \\
\hline Marcelo Santos & Pró-Vale & MDB & Governo \\
\hline Bruno Lamas & Pró-Vale & PSB & Oposição \\
\hline Nunes & Pró-Vale & PT & Governo \\
\hline Hudson Leal & Pró-Vale & PRP & Governo \\
\hline Gildevan Fernandes & Pró-Vale & PV & Governo \\
\hline Sandro Locutor & Inativo & PPS & Governo \\
\hline Padre Honório & Pró-Vale & PT & Governo \\
\hline Rodrigo Coelho & Inativo & PT & Governo \\
\hline
\end{tabular}

Fonte: Elaboração própria com dados do Tribunal Superior Eleitoral.

A maior parte das proposições dos deputados, sobre o caso do rompimento da barragem, em geral, visavam benefícios à empresa. Duas proposições, sobre a retomada das atividades da empresa e o fim de uma Comissão Parlamentar de Investigação (CPI), 
flagrantemente positivas aos interesses da Vale, foram assinadas por todos os deputados aqui classificados como Pró-Vale.

\section{CONSIDERAÇÕES FINAIS}

Se tomarmos por base Smith (1995, p.94), temos um comportamento bastante peculiar. O autor afirma que a capacidade de cooptação dos entes privados pelo Estado não é realizada em temas de grande relevância midiática. No caso do rompimento da barragem da Samarco, temos, justamente, o contrário. Os prejuízos causados pela lama despertam o interesse da mídia de forma contínua, embora, esta se detenha mais à descrição dos fatos do que propriamente à análise crítica do comportamento dos atores envolvidos no rompimento.

Outro ponto que também remete à contrariedade às observações de Smith é o interesse da Sociedade Civil. Em seu texto, o pesquisador conclui que, quanto mais a Sociedade Civil ignora determinada pauta, mais ela é suscetível a jogos de influência do capital. No caso da Samarco, novos movimentos surgiram a partir dos prejuízos causados à população. Estes, com frequência, realizam manifestações e cobranças públicas sobre a necessidade do estabelecimento de políticas públicas que visem diminuir o impacto causado pelos rejeitos em suas comunidades.

Esse texto procurou responder à hipótese de que os parlamentares foram cooptados pela Capital, no caso a Vale/Samarco, para atuarem conforme ditam seus interesses privados. Esse contexto não seja novo, a primeira parte deste texto traz observações seculares de Marx e Engels, o caso ainda é útil para entendermos o Estado e suas interferências.

\section{BIBLIOGRAFIA}

COTRIM, L. A arma da crítica: política e emancipação humana na Nova Gazeta Renana. In: MARX, K. Nova Gazeta Renana. São Paulo, EDUC, 2010.

DINIZ \& BOSCHI, R. Empresários, Interesses e Mercado: Dilemas do Desenvolvimento no Brasil. Belo Horizonte, Ed UFMG, 2004.

LINDBLOM, C. E. Politics and Markets: The World's Political-Economic Systems. New York: Basic, 1977. 
LUKÁCS, G. Estetica - La peculiaridad de lo estetico. v. I., México, Ed. Grijalbo, 1966.

. O jovem Marx e outros escritos filosóficos. Rio de Janeiro, UFRJ, 2007.

MARX, Karl. O capital. v. I. São Paulo, Abril Cultural, 1988.

O capital. v. II. São Paulo, Nova Cultural, 1988 b.

A revolução antes da revolução. São Paulo, Expressão Popular, 2009 b.

MARX, K; ENGELS, F. A ideologia alemã. São Paulo, Martins Fontes, 2002.

NICOLAU, Jairo. Como Controlar o Representante?: Considerações sobre as Eleições para a Câmara dos Deputados no Brasil. Dados [online]. Vol. 45, n. 2, p. 219-236. ISSN 0011-5258, 2002.

PASUKANIS. E. B. A teoria geral do direito e o marxismo. Rio de Janeiro, Renovar, 1989.

SAMUELS, David. Ambition, Federalism, and Legislative Politics in Brazil. New York, Cambridge University Press, 2003.

SMITH, Richard. "Interest Group Influence in the U.S. Congress" in: Legislative Studies Quarterly, Vol. 20, № 1, 1995.

TRINER, Gail D. Mining and the State in Brazilian Development. [Londres]: Pickering and Chatto. Disponível em:

<http://www.rci.rutgers.edu/ triner/UFFseminar/Triner4\&5\%202.pdf>. 2011.

ZONTA, M. e TROCATE, C. (Orgs.). Antes fosse mais leve a carga: reflexões sobre o desastre da Samarco/ Vale/ BHP Billiton. Marabá, Editorial iGuana, 2016.

ZORZAL E SILVA, Marta. A Vale do Rio Doce na estratégia do desenvolvimento brasileiro. Vitória: Editora da Universidade Federal do Espírito Santo - EDUFES, 2004. 